\title{
Engineering chimeric antigen receptor-T cells for cancer treatment
}

\author{
Baixin Ye ${ }^{1}$, Creed M. Stary ${ }^{2}$, Xuejun $\mathrm{Li}^{3}$, Qingping Gao ${ }^{1}$, Chunsheng Kang ${ }^{4^{*}}$ and Xiaoxing Xiong ${ }^{5^{*}}$ (D)
}

\begin{abstract}
Intratumor heterogeneity of tumor clones and an immunosuppressive microenvironment in cancer ecosystems contribute to inherent difficulties for tumor treatment. Recently, chimeric antigen receptor (CAR) T-cell therapy has been successfully applied in the treatment of B-cell malignancies, underscoring its great potential in antitumor therapy. However, functional challenges of CAR-T cell therapy, especially in solid tumors, remain. Here, we describe cancer-immunity phenotypes from a clonal-stromal-immune perspective and elucidate mechanisms of T-cell exhaustion that contribute to tumor immune evasion. Then we assess the functional challenges of CAR-T cell therapy, including cell trafficking and infiltration, targeted-recognition and killing of tumor cells, T-cell proliferation and persistence, immunosuppressive microenvironment and self-control regulation. Finally, we delineate tumor precision informatics and advancements in engineered CAR-T cells to counteract inherent challenges of the CAR-T cell therapy, either alone or in combination with traditional therapeutics, and highlight the therapeutic potential of this approach in future tumor precision treatment.
\end{abstract}

Keywords: Tumor ecosystem, Intratumor heterogeneity, T-cell exhaustion, Cancer immunotherapy, Chimeric antigen receptor (CAR) T cell therapy

\section{Background}

The diagnostic, monitoring and therapeutic options of cancers remain limited, resulting in a persistent threat to human health, and an urgent need for effective alternative therapeutic measures. Recently, cancer immunotherapies including the anti-programmed cell death protein-1 (PD-1) therapy and the genetically modified T-cell adoptive therapy, have gained headway in the field of cancer therapy [1-6]. In an antitumor immune response, cytotoxic T-lymphocytes (CTLs, a critical subset of effector T-cells) can mediate antitumor immunity through the induction of cytolysis or apoptosis of malignant cells in a human leukocyte antigen (HLA)-dependent manner. However, cancer cells use multiple pathways to evade CTLmediated antitumor immunity, evolving resistance to currently available combinational therapies, and resulting in cancer relapse or treatment failure [7]. Tumor heterogeneity

\footnotetext{
* Correspondence: kang97061@tmu.edu.cn; xiaoxingxiong@whu.edu.cn ${ }^{4}$ Lab of Neuro-Oncology, Tianjin Neurological Institute, Key Laboratory of Post-Neuroinjury Neuro-repair and Regeneration in Central Nervous System, Tianjin, China

${ }^{5}$ Department of Neurosurgery, Renmin Hospital of Wuhan University, Wuhan, Hubei 430060, China

Full list of author information is available at the end of the article
}

contributes to the complexity and difficulty of clinical management in antitumor immunotherapy [8-10]. As reported previously, the tumor ecosystem, which is in a state of symbiosis [10], contains heterogeneous cell types including tumor clones with varied spatial, functional as well as genomic characteristics, and associated components that include stromal cells and immune cells [8]. The complex interplay between the multicellular components of the tumor ecosystem play a critical role in tumor development. According to this "tumor ecosystem" theory, therapeutics that target malignant clones, stromal cells and immune cells at multiple layers may represent a potential approach for individualized cancer treatment, highlighting the importance of dissecting the multicellular tumor ecosystem from a clonal-stromal-immune perspective [8-11].

Engineered chimeric antigen receptor (CAR) genetransduced T-cell (CAR-T) therapies have shown great promise in the advancement of individualized clinical cancer immunotherapy. Recently, Novartis' Kymriah (tisagenlecleucel) became the first FDA-approved CAR$\mathrm{T}$ therapy in the treatment of relapsed or refractory B-cell acute lymphoblastic leukemia in the United State, highlighting the success of CAR-T cell-based 
immunotherapy [12]. CAR-T cells can be engineered to kill malignant cells specifically or remodel the tumor microenvironment through the release of soluble factors that then regulate the function of stromal cells or immune cells [13-15], providing a powerful tool to target multiple components of the tumor ecosystem. CARs, which contain a fusion protein that is composed of an antibody derived extracellular single-chain variable fragment $(\mathrm{scFv})$ with an antigen recognition moiety and an intracellular T-cell activation domain, can bind to the specific surface tumor antigens and mediate the killing of the tumor cells in an HLA-independent manner. Several clinic trials have demonstrated that CD19-targeted CAR-T-cell-based adoptive immunotherapy leads to a longer remission than current standard combination therapies, particularly in patients with CD19-positive B-cell malignancies including acute lymphoblastic leukemia (ALL), chronic lymphocyte leukemia (CLL) and some lymphomas [14, 15]. In addition to targeting and killing tumor clones directly, CAR-T cells have been utilized as a delivery system to carry effector drugs or proteins to the tumor site locally [16-19]. Despite these advances, functional challenges remain in the effective employment of engineered CAR-T cells for treating malignant diseases, especially for solid tumors. With the recent advancement of Next-Generation sequencing or mass spectrum technologies, treatments targeting tumor ecosystems with high intratumor heterogeneity can adapted to account for tumor clonality and other multicellular components that shape immunosuppressive microenvironment $[8,20,21]$. This potential approach utilizes precision informatics to identify the specific challenges in individual patients, and provides the possibility of precise design and optimization of potential CAR-T cell-based therapeutics or combination therapy in cancer treatment. Genome-editing and molecular engineering technologies also have great potential to equip CAR-T cells with the expression of multifaceted functional genes to counteract these functional challenges [22]. Alone or in combination with other therapeutic modalities, CAR-T cell therapy therefore holds great promise for cancer treatment.

Previously, we have reviewed the mechanisms of tumor immune evasion and the advances in genetically modified $\mathrm{T}$ cell-based immunotherapy [23]. In the present review, we will describe the concepts of tumor ecosystem, distinct cancer-immune phenotypes and Tcell exhaustion in immune evasion, providing a deeper and more detailed understanding on tumor immunity from a clonal-stromal-immune perspective. Then, we will review the functional challenges of engineering CAR-T cells, and generalize the framework of engineering and optimizing therapeutic CAR-T cells, alone or in combination with other therapeutics such as chemotherapy, radiotherapy and antibody-based therapy for future cancer treatments.

\section{Tumor ecosystem and cancer-immune phenotypes}

The tumor ecosystem is defined by a close interaction and crosstalk between heterogeneous tumor clones and heterogeneous stromal cells (for example, endothelial cells, cancer-associated fibroblasts) as well as immune cells (for example, T- or B- cells, macrophages), which shape tumor development in both the dynamic temporal and spatial dimensions [8]. During the process of tumor generation, tumor initiating clones can interact with their surrounding stromal cells or immune cells within the tumor microenvironment, resulting in the generation of premalignant cells [24]. Upon acquisition of secondary genetic and epigenetic alterations, premalignant clones undergo evolutionary adaptive processes to differentiate into heterogeneous tumor subclones, which are characterized by the expression of different classes of surface markers or intracellular neoantigens. In this complex multicellular ecosystem, all of tumor clones and nonmalignant cells exhibit a state of symbiosis, which cooperate to promote tumorogenesis. For example, in B precursor cell-acute lymphocytic leukemia (B-ALL, Fig. 1a), leukemia clones can integrate multiple signals from the niche cells including endothelial cells and immune cells, promoting leukemia evolution, development and relapse [24, 25]. Similarly, in the multicellular ecosystem of solid tumors (Fig. 1b), it was revealed that the branched evolutionary patterns of tumor clones and the heterogeneous suppressive microenvironment, which can be identified at different tumor sites in the individual patients, produce a high intratumor heterogeneity [21, 26-28], challenging the identification of the specific tumor antigens for targeted killing of tumor cells. Moreover, the tumor microenvironment is itself highly heterogeneous in the composition and function of stromal cells or immune cells $[8,20,21,29]$, helping to create an immunosuppressive microenvironment that promotes cancer pathogenesis.

Elucidating the multicellular tumor ecosystem is a first step in employing precision informatics for the design of antitumor immunotherapy. Recently, single-cell sequencing technology has enabled in-depth analysis of the varied types of cells in tumor ecosystem, allowing a more precise determination of heterogeneous tumor clones, their interaction with stromal cells, and the general cancer immune-microenvironment [20, 21]. For example, Zheng, et al. performed deep single-cell RNA sequencing on 5063 single T-cells isolated from hepatocellular carcinoma (HCC) patients, revealing distinctive functional composition of infiltrating T-cells. They found that HCC tissues are distributed with infiltrating regulatory $\mathrm{T}$-cells (T-regs) and exhausted $\mathrm{CD} 8^{+} \mathrm{T}$ cells, the immunosuppressive function of which is closely related with LAYN gene expression in HCC [21]. Dissection of cancer ecosystems through single-cell sequencing technology indicates that tumor infiltrating lymphocytes 


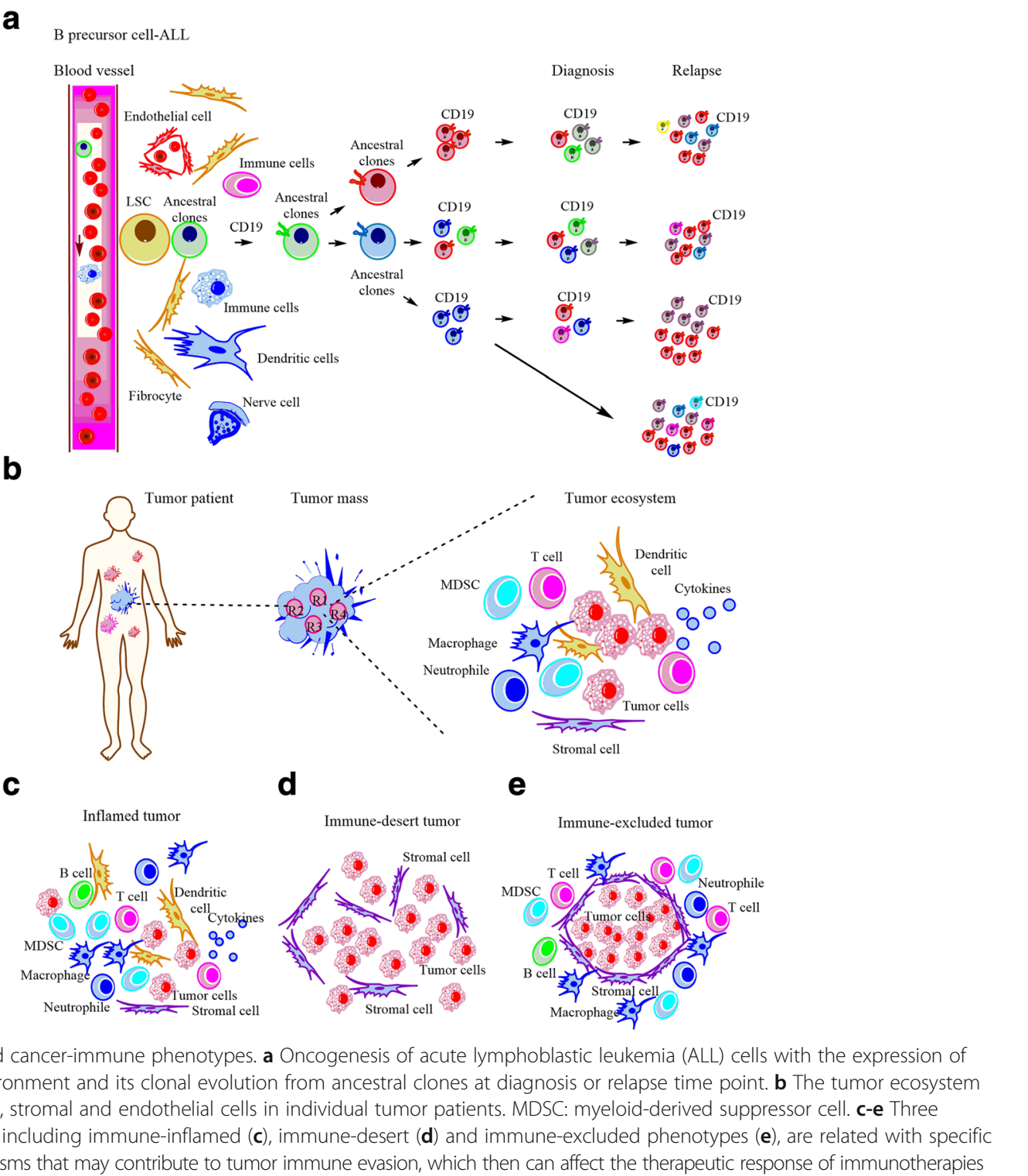

Fig. 1 Tumor ecosystem and cancer-immune phenotypes. a Oncogenesis of acute lymphoblastic leukemia (ALL) cells with the expression of CD19 in leukemia microenvironment and its clonal evolution from ancestral clones at diagnosis or relapse time point. $\mathbf{b}$ The tumor ecosystem contains malignant, immune, stromal and endothelial cells in individual tumor patients. MDSC: myeloid-derived suppressor cell. c-e Three cancer-immune phenotypes including immune-inflamed (c), immune-desert (d) and immune-excluded phenotypes (e), are related with specific underlying biological mechanisms that may contribute to tumor immune evasion, which then can affect the therapeutic response of immunotherapies

(TILs) with exhaustion programs exhibit suppressive immune function that kill cancer cells by integrating signals from the tumor microenvironment. Further, Tirosh et al. applied single-cell sequencing technology to profile the malignant, immune, stromal and endothelial cells in tumor tissues for the dissection of multicellular ecosystems of metastatic melanoma, providing a more precise characterization of infiltrating T-cell activation, expansion, exhaustion and variability across patients [8]. These works suggest that a greater understanding of the tumor ecosystem has promoted a shift of cancer therapeutic paradigms from "a clonal perspective" to "a clonal-stromal-immune perspective" [30]. This is represented as a focus not only on tumor clones, but also on the local immunosuppressive microenvironment, towards eliciting an effective antitumor response [11].

Distinct tumors utilize different mechanisms to evade immunity, resulting in the production of distinct cancerimmune phenotypes at a multicellular ecosystem level. In the tumor ecosystem, TILs that traffic and infiltrate into the tumor parenchyma are considered a positive biomarker for cancer treatment and prognosis [31-34]. With the presence of TILs in tumor parenchyma, cancer-immune phenotypes can be described and divided into an immune-inflamed phenotype, an immunedesert phenotype and an immune-excluded phenotype, which is closely related with the therapeutic response to immunotherapies such as anti-PD-1/PD-L1 therapy (Fig. 1c-e) [35, 36]. It has beem previously demonstrated 
that specific cancer-immune phenotypes have distinct immune response to immunotherapies, suggesting that cancer cells utilize a variety of mechanisms to escape immunity-mediated killing [35]. More specifically, the immune-inflamed phenotype is characterized by the infiltration with many types of immune cells including regulatory T-cells, $\mathrm{CD}^{+}$or $\mathrm{CD}^{+}{ }^{+}$lymphocytes, suppressor B cells, myeloid-derived suppressor cells and cancerassociated fibroblasts (Fig. 1c), which comprise the tumor ecosystem that precedes the antitumor immune response to treatment. Alternatively, the immune-desert phenotype refers to an immune profile described by a paucity of immune cells, especially the cytotoxic $\mathrm{T}$ lymphocytes, in either the parenchyma or the stromal of tumor tissue (Fig. 1d). It has been suggested immunological ignorance, tolerance, or a lack of T-cell priming and activation contribute to a lack of pre-existing antitumor response. Finally, the immune-excluded phenotype is characterized by the presence of abundant lymphocytes in the stroma in the absence of infiltration into the parenchyma of tumors. This effect leads to failure of CTLmediated eradication of tumor clones due to the dislocation of an antitumor immune response, and impaired migration of lymphocytes into the parenchyma of tumor tissue by surrounding stromal cells [35, 37, 38] (Fig. 1e). Either immune-excluded or immune-desert phenotypes are considered non-inflammatory tumors from the clonalstromal-immune perspective, which can be co-applied as a potential biomarker to predict the immune response upon immunotherapy. For example, it was recently reported that anti-PD-1/PD-L1 therapy can produce a more effective therapeutic response in the immune-inflamed cancers than in non-inflammatory cancers, suggesting that identification of the appropriate cancer-immune phenotype is helpful for the prediction of therapeutic response to immunotherapy [39]. Therefore, a more detailed dissection and description of the tumor ecosystem and deeper understanding of the tumor immune profile is necessary for the development and optimization of novel and effective cancer immunotherapeutics.

\section{Cancer-immunity cycle and T-cell exhaustion}

In adaptive immunity, APCs including dendritic cells, macrophages and subsets of $B$ cells, process antigens in an HLA-dependent manner, which can be targeted by antigen-specific CTLs providing co-stimulatory signals for priming an antigen-specific CTL response [7, 40]. In the normal cancer-immunity cycle (Fig. 2a), tumor antigens released by destroyed cancer cells can be presented by antigen-presenting cells (APCs), followed by T-cell activation, trafficking and infiltration of effector T-cells into tumor cells, and recognition and targeting of cancer cells with subsequent release of tumor antigens [41]. During the cycle of the $\mathrm{T}$-cell antitumor response, the cancer-immune set point, which is referred to as the threshold that is dependent on the balance between the stimulatory and inhibitory factors in the cancer ecosystem, determines the priming and activation of effective anti-tumor immunity [36]. However, as a result of inhibitory factors in the tumor ecosystem, an effective antitumor T-cell response can be inhibited at several points of the cancer-immunity cycle, thereby promoting tumor cells to evade from immunity-mediated killing. According to the clonal-stromal-immune perspective, the interplay and crosstalk between tumor clones, stromal cells and immune cells in the multicellular ecosystem play a critical role in effector $\mathrm{T}$-cell response and tumor evasion [30]. First, tumor clones with heterogenous mutation-derived neoantigens are involved in the cancer-immunity cycle [7]. Neoantigens that can be processed and presented by APCs can elicit an efficient T-cell response. It was recently reported that the clonal neoantigens exhibit greater efficiency than the heterogenous neoantigens in eliciting an effective immune response $[42,43]$, suggesting that distinct tumor clones with heterogenous neoantigens can affect the T-cell response. Second, stromal cells, such as endothelial cells and nerve cells, can release tumor progression-related soluble factors, including cyclooxygenase-2 (COX-2) [44, 45], prostaglandin $\mathrm{E}_{2}\left(\mathrm{PGE}_{2}\right)[45,46]$, transforming growth factor- $\beta$ (TGF- $\beta)[47,48]$ and vascular endothelial growth factor (VEGF) [49], which can regulate the T-cell response at multiple stages of cancer-immunity cycle. Third, in the tumor niche, the varied types of immune cells including APCs, T-regs, tumor-associated macrophages (TAMs) and myeloid-derived suppressor cells (MDSCs) [50], constitute the complex immune microenvironment that can shape the cancer-immunity cycle [51]. Therefore, targeting the effector T-cell response in the normal cancer-immunity cycle is critical for the eradication of tumor clones.

However, as reviewed previously, multiple pathways lead to tumor immune evasion and cause failure of treatment [23]. Within the tumor ecosystem, several immunosuppressive factors lead to a poor response of T-cells, termed "T-cell exhaustion," that mediates tumor immune evasion and serves as an impediment of the normal cancer-immunity cycle [52, 53] (Fig. 2b). The phenotype of $\mathrm{T}$-cell exhaustion is characterized by reduced T-cell proliferation, increased expression of inhibitory receptors (for example, programmed cell death protein-1(PD-1), cytotoxic T-lymphocyte antigen-4 (CTLA-4), lymphocyte activation gene 3(LAG-3), decreased production of stimulatory cytokines (for example, IL-2, IFN- $\gamma$, TNF- $\alpha$.) and compromised cytotoxicity. In general, exhausted T-cells are a distinct lineage from memory or effector CTLs, and can possibly differentiate into defective memory or physical deletion T-cells. From the clonal-stromal-immune perspective, the generation of dysfunctional 
a

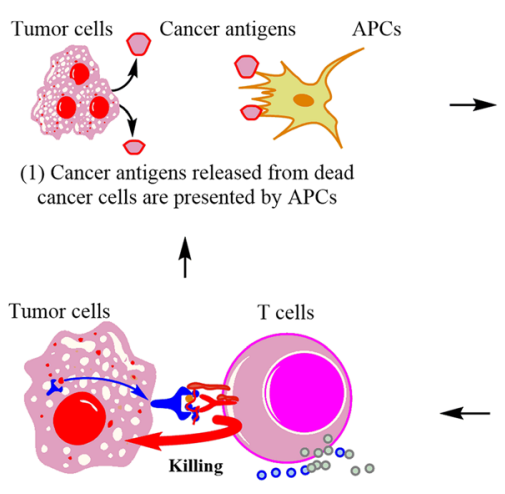

(4) Recognition and killing of cancer cells by activated $\mathrm{T}$ cells specifically

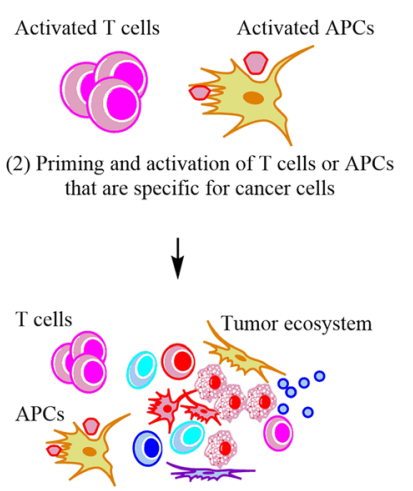

(3) Trafficking and Infiltration of activated T cells or APCs to tumor site

b

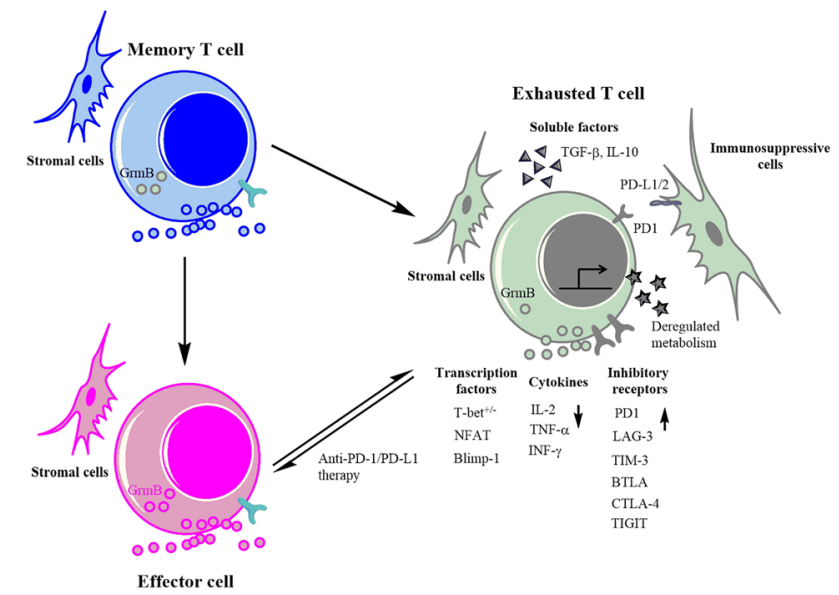

Fig. 2 Cancer-immunity cycle and T-cell exhaustion in the tumor ecosystem. a Cancer-immunity cycle. Cancer antigens that are derived from destroyed cancer cells are engulfed and presented on the surface of antigen presenting cells (APCS), followed by the priming and activation of Tcells and APCs specific for cancer antigens. Upon activation of effector T-cells or APCs, the effector T-cells bearing cancer antigen-specific TCRs traffic and infiltrate into the tumor sites, recognize cancer cells with the expression of these antigens, and mediate the targeted-killing of cancer cells, which can be processed and presented by APCs in turn. b T-cell exhaustion in the tumor ecosystem. T-cell exhaustion refers to the dysfunctional and hypo-responsive state of T-cells, characterized by reduced proliferation and cytokine production, as well as impaired cytotoxicity due to decreased expression of granzyme B. Memory and effector T-cells can differentiate into exhausted T-cells in the tumor ecosystem consisting of tumor clones, stromal cells and immune cells, which can provide internal and external signals for T-cell exhaustion. The internal signals of T-cells in exhaustion are attributed to the enhanced expression of inhibitory receptors (for example, PD-1, CTLA-4, TIM-3, LAG-3, BTLA and TIGIT), the decreased release of immunostimulatory cytokines (IL-2, TNF-a, IFN- - ) and the transactivation of transcription factors (T-bet ${ }^{-/+}$, NFAT, Blimp-1). External signals of exhausted T-cells are from soluble factors (TGF- $\beta$, IL-10), stromal cells that can secrete cytokines, immunosuppressive cells (eg. Macrophages and dendritic cells) and deregulated metabolism in the tumor ecosystem. Early exhausted T-cells can be reversed to effector T-cells with treatment of anti-PD-1/PD-L1. TIM-3: T cell immunoglobulin and mucin domain containing-3; BTLA: B and T lymphocyte attenuator; TIGIT: T cell immunoreceptor with Ig and ITIM domains; NFAT: nuclear factor of activated T cell; Blimp-1: B lymphocyte-induced maturation protein 1

CTLs in exhaustion can be attributed to multiple complex components of the tumor ecosystem [8,21], including intracellular signals from inhibitory receptors and altered CTL transcriptional activation, as well as alteration in extracellular signals from tumor, stromal and immune cells such as macrophages, dendritic cells, T-regs and myeloid-derived suppressor cells $[52,53]$. Additionally, soluble factors such as TGF- $\beta$ and IL-10, as well as the metabolic status of the tumor ecosystem such as hypoxia, hypoglycemia and amino acid deletion, can all contribute to T-cell exhaustion [52, 53]. For example, the expression of PD-1 on the surface of CTLs and its ligand PD-L1 on the tumor, stromal or dendritic cells are upregulated, resulting in enhanced PD-1/PD-L1 signals that are considered a critical factor regulating effector function of CTLs to an exhausted phenotype. As reported previously [36], exhausted effector T-cells that express relatively low amounts of PD-1 at early stages can be reversed to a functional state with anti-PD-1/PD-L1 therapy, while the hyper-exhausted effector T-cells with relatively high expression of PD-1 are not recoverable. This observation suggested that exhausted T-cells can be reactivated through early treatment. Therefore, strategies targeting $\mathrm{T}$-cell exhuastion at 
early stages for reactivation of the normal cancer-immunity cycle are promising for the successful treatment of maligancies $[30,54]$.

\section{Advances and challenges in CAR-T cell-based adoptive therapy \\ Advances in CAR-T cell therapy}

Impaired target-recognition of CTLs to tumor cells can result in immune evasion. Therefore, redirecting the specificity of CTLs to tumor antigens is increasingly recognized as a requirement for cancer immunotherapy [7]. Neoantigen-specific T-cells that naturally exist in cancer patients are difficult to identify and isolate, and the function of T-cells is often disrupted, limiting the application of TIL-based adoptive immunotherapy [22]. However, it was observed that the expression of a novel immunoglobulin-derived zeta chain fusion receptor that is specific for the prostate cancer antigen "prostate-specific membrane antigen (PSMA)" in normal Tlymphocytes confer the specificity and killing-capacity of the T-lymphocytes to prostate cancer cells [55]. This generation of genetically engineered T-lymphocytes transduced with artificial antigen-specific receptors suggests the feasibility of adoptive cell therapy in cancer treatment $[54,56]$. Currently, on the basis of technological advancements in genome editing [22, 57], gene transfer and cell culture, the rapid improvement in the generation of genetically modified and patient-derived T-cells bearing CARs has provided a robust platform for the targeted therapy through redirecting the specificity of CTLs against tumor cells [22] (Fig. 3a).

CARs (Fig. 3b), which contain an extracellular ScFv for antibody-like antigen recognition and intracellular signaling domains for $\mathrm{T}$-cell activation from the TCR signaling complex, are genetically modified receptors transduced and expressed in human CTLs for the binding to the surface antigens of tumor cells in their native conformation $[14,15,58]$. In CAR-T cell-mediated immunity, the $\mathrm{ScFv}$ can engage surface antigens of tumors directly via antibody-like binding in an HLAindependent manner [15], which is not limited and compromised by impaired processing and presentation of tumor antigens in tumor cells or APCs [14]. The intracellular signaling domains of CAR, which combine the co-stimulatory domains such as CD28 or 4-1BB $[59,60]$, can be fused with $\mathrm{T}$-cell activating signaling transduction domains such as $\mathrm{CD} 3 \zeta[14,54,61]$, providing necessary signals for eliciting T-cell activation [15]. As reviewed in our previous report [23], the structure of intracellular signaling domains in CARs has undergone three "generations" of development [15] (Fig. 3b). The 1st-generation CARs contained only $\mathrm{CD} 3 \zeta$ transduced into the intracellular signaling domains for transmitting an activator signal to the downstream signaling components. The 2nd-generation CARs contained $\mathrm{CD} 3 \zeta$ and one costimulatory domain derived from CD28 or 4-1BB, leading to dramatic clinical improvement as a result of release of cytokines and anti-apoptotic factors upon antigen engagement $[14,59]$. Further studies indicated that CARs incorporating 4-1BB derived domain, but not CD28, could ameliorate tonic CAR signaling-induced Tcell exhaustion, thus improving CAR-T cell proliferation and persistence [62]. To further improve efficacy, a 3rd-generation CAR construct consisting of multiple costimulatory signaling domains including CD28 [59], 41BB [60], OX40 [63] and ICOS [64, 65] has been recently developed, although the effect on long-term overall and event-free survival among patient groups remains to be further investigated [14]. Interestingly, W.A. Lim's group recently demonstrated that a novel synthetic Notch (synNotch) receptor that is engineered in primary T-cells supplies a flexible method to induce customized immune responses [16] (Fig. 3b). Similar with CARs, the synNotch receptor contains a synthetic extracellular recognition domain (e.g., scFv), a core regulatory domain from the cell-to-cell signaling receptor Notch, and a synthetic intracellular domain that can induce downstream transcription. Upon engagement of the extracellular domain of synNotch receptor with a specific antigen on tumor cells, the intracellular domain of the synNotch receptor is cleaved and released into the nucleus of T-cell, thereby activating expression of target genes and inducing an antitumor response. In comparison with CARs that can directly drive T-cell activation, the synNotch receptor functions in a similar antigen-dependent manner but in a T-cell activation-independent manner. As an alternative type of chimeric receptor, the synNotch receptor provides a general platform for engineering primary T-cells to locally deliver non-native therapeutic payloads, remodel the tumor microenvironment and monitor the T-cell immune response. In combination with synNotch receptors, CAR-T cells can be genetically modified to improve their effectiveness and safety profile by sensing environmental factors and modulating T-cell activity [19, 54]. Therefore, CAR-T cells can be engineered not only to mediate specific and effective CTL-mediated killing of tumor cells, but also to exhibit custom response programs in primary T-cells in combination with synNotch receptors [15].

CD19-targeted CAR-T cell-based adoptive immunotherapeutics serve as a successful therapeutic example in patients with relapsed B-cell malignancies, including $B$ precursor cell -ALL, CLL and non-Hodgkin lymphomas in clinic trials $[6,14,15,66,67]$. In the development of B-cell malignancies such as B-ALL (Fig. 1a) [68], malignant initiating clones with expression of CD19 molecule (ubiquitously expressed in normal B cells) can differentiate into highly heterogeneous subclones at the genetic 
a

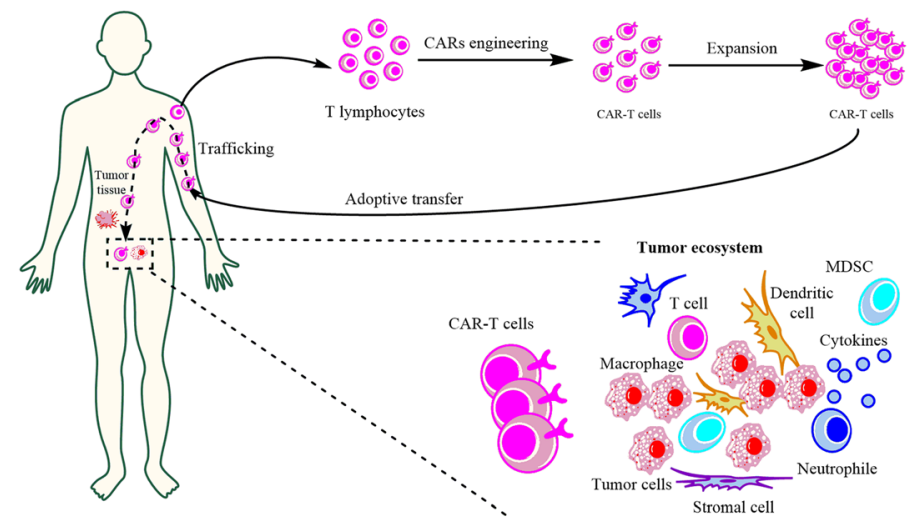

b
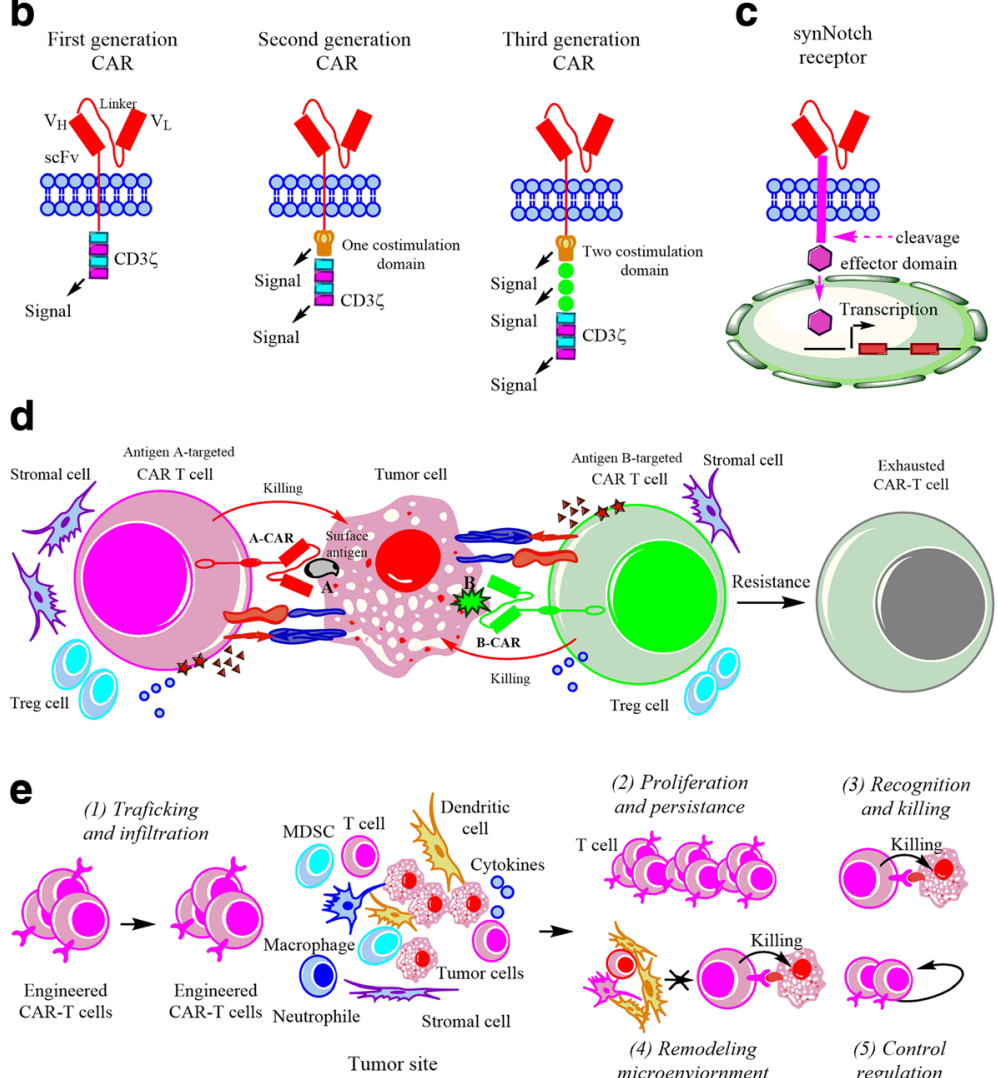
(3) Recognition
and killing

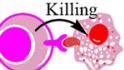

Fig. 3 The CAR-T cell therapy and its functional challenges. a Procedures of CAR-T cell-based immunotherapy and their trafficking to, and infiltration of, the tumor site. $\mathbf{b}$ Three generations of CAR structures and the synNotch receptor system. Upon the engagement of tumor surface antigens with extracellular scFv domains, CARs with the intracellular CD3Z-costimulation (CD28 or 4-1BB) domain can induce native T-cell activation. c The synNotch receptor with Notch domain-mediated cleavage and release of specific transcription factors can initiate custom transcription programs upon engagement of surface antigens. $\mathbf{d}$ CAR-T cells recognize and kill the tumor cells. Different tumor-specific antigen-targeted CAR-T cells can combine to recognize and kill the tumor clones, resulting in enhanced potency and improved clinical outcome. Antigen A-targeted and antigen B-targeted CAR-T cells combine to kill the tumor cells bearing the antigen A and B. Additionally, CAR-T cells can differentiate into the exhausted state, promoting the emergence of therapeutic resistance. e Challenges in CAR-T cell-based immunotherapy involve CAR-T cell trafficking and infiltration, adequate CAR-T cell proliferation and persistence, targeted recognition and killing of tumor cells, remodeling of the immunosuppressive microenvironment and self-control regulation

and epigenetic levels, resulting in difficulties of T-cell therapy for their eradication. For example, given that Tcell recognition of tumor cells occurs in a HLAdependent manner, malignant subclones become not targetable due to downregulation of HLA molecules, thereby evading T-cell immunity-mediated elimination. Fortunately, nearly all malignant B-ALL clones express CD19 at initial diagnosis or even relapse phase, providing the basis for CD19 as an ideal therapeutic target in CAR$\mathrm{T}$ cell therapy for the following reasons [14]: first, CD19 is 
expressed in nearly all B-cell malignant clones, which serves as a unique and achievable target for CAR-T cell therapy [14, 69]. Second, normal CD19-expressing B-cells are also possibly killed by CD19-targeted CAR-T cells, but this on-target off-tumor effect does not usually produce clinically unmanageable symptoms [13], providing the basis for clinical applications. Indeed, upon eradication of malignant B-cells, the normal B-cells are also eliminated. Unexpectedly, this loss of normal B-cells is tolerable with combined antibody replacement therapy [14, 54]. Moreover, B-cell aplasia usually occurs in patients with successful CAR-T cell treatment, whereas the persistence of normal B-cells is usually associated with a higher incidence of therapeutic failure [70]. Third, CD19-CAR Tcells showed a delayed early exhaustion, which confers the therapeutic T-cells with the increased capacity of proliferation and persistence [62]. In despite of the early success of CD19-targeted CAR-T cell therapy in B-cell malignancies $[14,54]$, CAR-related toxicities, including cytokine release syndrome (CRS) and neurological toxicities [23] challenge the development and popularity of CAR-T cell therapy. Additionally, CD19-targeted CAR-T cell therapy also displayed off-target effects and treatment failure due to the disappearance of the targeted epitope on CD19 in about $14 \%$ patients, suggesting that antigen loss can be a significant problem in CAR T-cell therapy. Therefore, these observations suggest that current CD19-targeted CAR-T cell approaches require further optimization.

The initial success of CD19-targeted CAR-T cell therapy highlights the importance of choosing optimal surface target antigens in CAR-T cell therapeutics. In addition to CD19 as a CAR target, several other surface tumor antigens have been also considered in CAR-T cell therapy. In ongoing clinic trials, the surface tumor antigens CD20 [71], CD30 [72], CD33 [73], CD123 [74, 75], CD38 [76], CD138 [77], Ig к light chain and Lewis-Y [78], have been applied as CAR targets, providing a pool of target antigen candidates in cancer treatment, although their clinical outcome remains further determined [15, 78-85]. More recently, cancer-associated Tn glycoform of MUC1, a neoantigen expressed on the cell surface in a variety of cancers, has also been targeted to engineered CAR-T cells and have been shown to be successful in controlling tumor growth in xenograft models of T-cell leukemia and pancreatic cancer [86, 87]. Additionally, CARs have been developed to recognize the intracellular neoantigens that are presented by HLA molecules on the tumor cell surface. For example, a recent report demonstrated that a novel CAR can selectively and specifically target the cell surface complex of the specific liver cancer marker alphafetoprotein (AFP) derived AFP158-166 peptide and HLAA*02:01 [88]. Another novel CAR that exerts a TCR-like function to bind the acute myeloid leukemia (AML)specific PR1/HLA-A2 complex has been recently developed to efficiently and rapidly kill AML cells in vitro, broadening the application of CAR-T cell therapy especially for those solid tumors with presentation of neoantigens in an HLAdependent manner [88-94]. Admittedly, in most tumors, intratumor heterogeneity contributes to the variation in the expression and mutation of tumor surface antigens, resulting in antigen loss and tumor relapse. It has also been suggested that CAR-T cells targeting dual or more surface tumor antigens may function to dramatically improve recognition specificity for tumor cells [95, 54, 96] (Fig. 3c). For example, combinational targeting CD19/CD22 antigens can efficiently promote the eradication of the $\mathrm{CD} 19^{+} \mathrm{CD} 22^{+}$, $\mathrm{CD} 19^{-}$, and $\mathrm{CD} 22^{-}$Pre-B leukemia clones, thus preventing the resistance to single CD19-targeted CAR-T cells in preclinical pre-B cell ALL models [95]. Most recently, Zhou's group also observed that sequential infusion of CD19 and CD22-targeted CAR-T cells combined to treat the patients with refractory/relapsed B-ALL, resulting in a decreased antigen escape relapse [96]. Therefore, identification and targeting specific tumor antigens show promise to optimize CAR-T cell-based immunotherapeutics.

In addition to directly killing tumor cells, CAR-T cells can deliver antitumor agents to kill tumor clones or remodel the tumor microenvironment in localized tumor sites. As reported by Boice et al. [18], the loss of HVEM (TNFRSF14) receptor gene that serves as a frequently mutated gene in germinal center lymphomas can be disrupted, thus promoting cell-autonomous B-cell proliferation and development of germinal center lymphomas in vivo. To reverse HVEM function, CD19-targeted CAR-T cells were engineered to locally and continuously produce the HVEM ectodomain protein in vivo, and exhibited an enhanced therapeutic activity against xenografted lymphomas. This study illustrated the application of CAR-T cells as a vector to deliver anti-tumor agents to localized and specific tumor sites, implicating the potential for improving efficacy and lowering toxicity of CAR-T cell therapy. This approach may also be potentially combined with synNotch receptor targeting (discussed above) for CD19-targeted or other antigentargeted CAR-T cells for the delivery of antitumor proteins in localized tumor sites $[16,19]$. Such combinatorial potential of CAR-T targeting highlights the clinical potential of their use as both a delivery system and specific antigentargeting system in cancer treatment.

\section{Challenges in CAR-T cell therapy}

The constantly evolving heterogeneity of cancer cells and their complex microenvironment represent a multifaceted hurdle for cancer immunotherapy and challenges remain in clinical application of CAR-T based approaches. For example, CAR-T cell therapy remains limited in the treatment of solid tumors such as adenocarcinoma and sarcoma [54, 86, 97], and in clinic trials of solid tumors, 
CAR-T cell therapies have exhibited limited efficacy and severe toxicity [98]. For example, CAR-T cells targeting CD19, folate receptor 1 alpha or CD171 in solid tumors, including lymphoma, ovarian cancer and neuroblastoma, showed severe toxicity, limited efficacy, or induction of host-directed immune responses [14, 15, 58, 99]. These limiting factors in clinic trials underscore the multidimensional challenges of CAR-T cells. Therefore, optimal measures promoting immune enhancement and/or reduced toxicity that utilize genetically modified $\mathrm{T}$ cellbased adoptive immunotherapy should be considered.

In general, five major classes of functional challenges should be considered in CAR-T cell therapy [54] (Fig. 3d). First, the trafficking and infiltration of CAR-T cells to tumor sites serves as an important limiting factor for effective CAR-T cell therapy. As described previously, the immunity-desert or immunity-excluded tumors that are characterized by the absence of lymphocytes in the parenchyma of tumors rarely respond to immunotherapeutics such as anti-PD-1/PD-L1 therapy. Similarly, the trafficking and infiltration of effector CAR$\mathrm{T}$ cells determines the therapeutic efficacy in solid tumors, although this might not be a major factor in hematological malignancies. It has been reported that, in solid tumors, the inefficient trafficking and infiltration of CAR-T cells typically results in the failure of treatment [54]. Additionally, CAR-T cells expressing introduced chemokine receptors have been observed in the tumor sites where the chemokines were released [100, 101], suggesting that trafficking and sub-regional infiltration of CAR-T cells is a critical step in their antitumor immune response.

Second, the proliferation and persistence of CAR-T cells influences their clinic efficacy [54]. In antitumor immunity, the expansion of infused CAR-T cells contributes to the required effector-to-target ratio for the targeted killing of tumor cells. However, exhausted CAR-T cells with impaired proliferation and persistence cannot efficiently kill malignant clones, usually leading to treatment failure [62]. 1st-generation CAR-T cells containing only the CD3 domain produced limited proliferation and persistence of T-cells $[98,102,103]$, while the 2nd-generation CAR-T cells incorporated an additional co-stimulatory signaling domain derived from $\mathrm{CD} 28$ or 4-1BB, and promoted T-cell proliferation and persistence $[14,59,78]$. It was previously reported that tonic $\mathrm{CAR} C D 3 \zeta$ phosphorylation induced by clustering of CAR scFv in an antigen-independent manner triggers the early exhaustion of CAR-T cells, thus lowering their proliferative and cytokine-producing capacities [62]. Therefore, maintaining the proliferation and persistence of T-cells is also critical for effective CAR-T cell therapy.

Third, targeted-recognition of CAR-T cells is critical for the killing of tumor cells. In antitumor immunity, T-cell recognition and killing of tumor cells in an
HLA-dependent manner is critical for an effective immune response, highlighting the importance of targetedrecognition by CTLs. Previously, the generalized view in immunotherapy was that cancer cells can evade the immunity-mediated killing and elimination through the downregulation or loss of HLA molecules expression, resulting in impaired processing and presentation of tumor antigens [7]. To avoid this dilemma, choosing desirable tumor surface antigens is significant for CAR-T cell therapy [15]. However, given that several tumor antigens are co-expressed in normal cells, the ideal specific tumor antigen targets cannot always be easily identified. CAR-T cells targeting non-specific surface antigens can produce cross-reactivity, resulting in the killing of normal cells and severe toxicity [54]. For example, CD19-targeted CAR- $T$ cells can target all of the malignant and normal CD19+ B cells, resulting in B cell aplasia and severe toxicity. Additionally, alternative surface tumor antigens such as CD20, CD30, CD33, CD123, CD38, CD138, Ig k light chain and Lewis-Y are accompanied with off-target binding. Therefore, identification of desirable surface tumor antigens remains a challenge for CAR-T cellmediated recognition and killing of tumor cells.

Fourth, according to clonal-stromal-immune perspective, the immunosuppressive microenvironment can limit and impair therapeutic CAR-T cell function. Previous clinical failures in immunotherapy for solid tumors can be partially attributed to the tumor immunosuppressive microenvironment $[104,105]$. It has also been observed that the deregulated activity of the enzyme indoleamine 2,3-dioxygenase (IDO) that converted tryptophan into metabolites can shape the immunosuppressive microenvironment and produce an impaired CAR-T cell function [106]. Therefore, the immunosuppressive microenvironment is a important factor limiting the wider applications of CAR-T cell therapy.

Finally, an uncontrolled CAR-T cell response typically leads to severe toxicity and adverse side effects [54, 107]. In clinic trials, the uncontrolled expansion and enhanced activation of therapeutic cells can lead to adverse off-target effects. Historically, control of expansion and function of infused T-cells has not been a primary focus [54]. This dilemma highlights the challenges of designing and engineering the feedback-control regulatory system of $\mathrm{T}$ cells for the optimization of therapeutic timing, strength and location of their activity $[107,108]$.

\section{Engineering CAR-T cells for individualized cancer treatment}

Counteracting the functional challenges of CAR-T cells through interventions at multiple dimensions

Basing on our growing understanding of the tumor ecosystem, functional challenges in specific types of cancers can be identified, promoting the advancements in the 
design and optimization of therapeutic T-cells for precision treatment [54]. More specifically, primary T-cells from tumor patients can be purified and then genetically targeted for counteracting functional challenges. As shown in Fig. 4a, the initial step in CAR-T cell-based precision therapy is to acquire precision informatics of the tumor cells and specific details of their microenvironment. Then, we can more precisely identify optimal therapeutic targets and engineer the therapeutic CAR-T cells with the capacity for targeted recognition and killing. By then applying tumor-specific CAR-T cells expressing multiple functional genes in a localized and controlled manner, we can then build a general platform to counteract the functional challenges in CAR-T cell therapy.

The first consideration is targeted trafficking and infiltration of CAR-T into the parenchyma of tumors, and

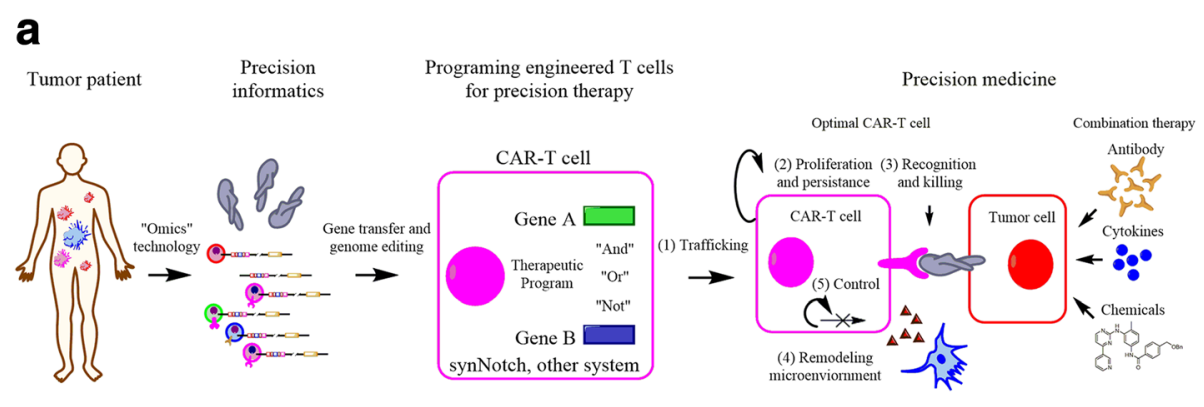

b
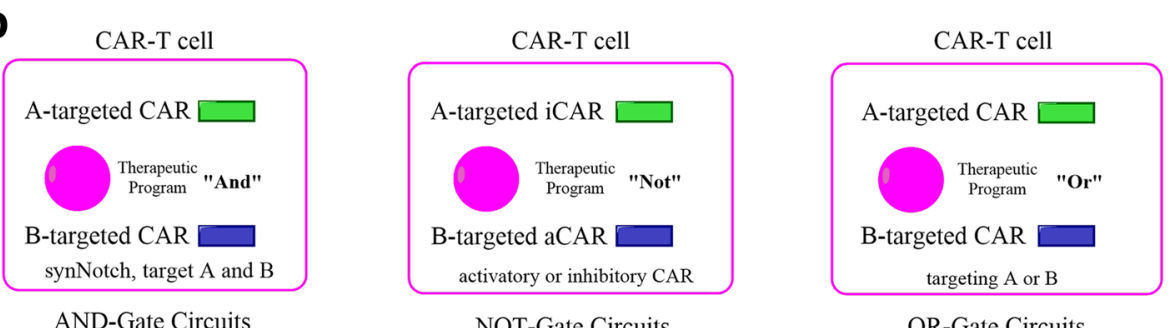

C Programing and engineering CAR-T cell
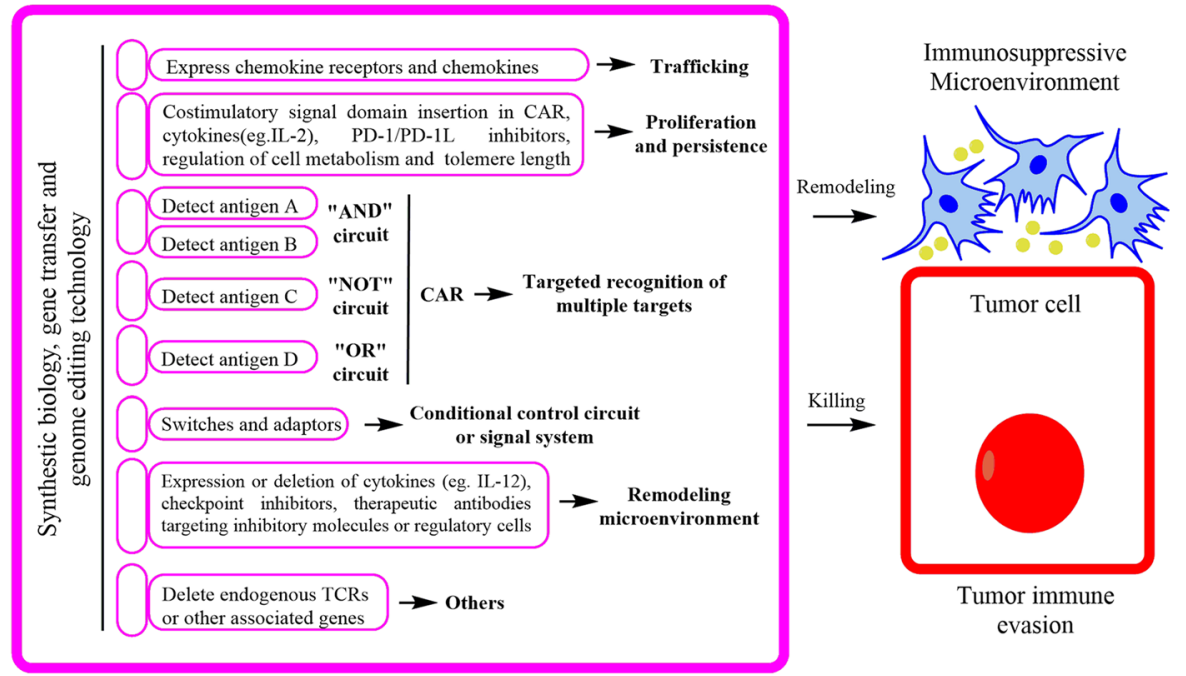

Fig. 4 Programming and engineering of CAR-T cell therapy for precision cancer medicine. a Procedures of precision informatics and precision therapeutics for precision cancer medicine. Through advanced diagnostic technologies including "omics" technologies for more detailed understanding of tumor clones and the microenvironment, precision informatics can counteract the challenges of engineering optimal CAR-T cells, including cell trafficking and infiltration, proliferation and persistence, recognition and killing, remodeling the microenvironment and self-control regulation. As well, a higher order understanding can promote the design of CAR-T cell therapies for use in combination with other therapeutics approaches that target the microenvironment, such as antibodies, chemicals and cytokines. b The CAR-based circuits for logical programming include the "AND", "NOT" and "OR"-Gated circuits, which provide improved recognition specificity through the integration of multiple antigens or combinational antigens. c Therapeutic programs for designing and engineering CAR-T cells to improve and optimize their functions include cell trafficking, proliferation and persistence, recognition and killing, remodeling microenvironment and self-control regulation 
engineered CAR-T cell can be applied as a tumortargeting delivery system for the localized and controlled expression of therapeutic factors that can regulate cell trafficking [16, 19]. For cell trafficking and infiltration, previous clinical trials have demonstrated that the incorporation and expression of chemokine receptor genes such as chemokine receptor 4 or 2 (CCR4 or CCR2), in CAR-T cells can promote their trafficking and infiltration into tumor sites, which is then required for effective T-cell mediated killing of tumor cells, especially in solid tumors [100, 109]. Moreover, through recent advances in T-cell chemotaxis and migration, promoting the infiltration of therapeutic CAR-T cells to desirable locations can be potentially achieved by incorporating genes of indicated chemokines or chemokine receptors.

The second important consideration is to improve the proliferation and persistence of CAR-T cells. It has been shown that driving CAR-T cell proliferation and persistence in vivo is a critical limiting factor for durable remission of leukemia, implicating a potential opportunity to improve the function of adoptively transferred T-cells via regulation of T-cell proliferation and persistence [78]. Expression of cytokines such as IL-2 in engineered T-cells, the incorporation of costimulatory signaling domains (eg. CD28 or $4-1 B B$ signaling domains) into CAR molecules [62], prolongation of CAR-T cells' lifespan through enhancement of telomere length or telomerase activity, modulation of T-cell exhaustion via interruption of PD-1 ligand binding, and reinforcement of lymphocyte metabolism have all been considered for improving $\mathrm{T}$-cell proliferation and persistence [54].

A third critical consideration is improvement in the tumor-targeted recognition ability of CAR-T cells. The great success of genetically modified TCRs or CARs has provided a platform to advance a broader range of intracellular tumor neoantigens. Given that cancer is a heterogeneous disease, bioinformatic analysis suggests that recognizing relatively simple combinations of multiple antigens would dramatically improve the capability of discriminating cancer cells and normal cells. This highlights the importance of CAR-based circuits including AND-Gate circuits, NOT-Gate circuits and OR-Gate circuits, which can integrate information about multiple antigens for the improvement of recognition specificity (Fig. 4b) [54]. In detail, AND-Gate circuits of T-cells bearing two independent antigen-targeting CARs allow the full activation of T-cells upon the engagement to both antigens distributed on the surface of tumor cells, which can improve the specificity of CAR-T cells to tumor clones. Recent advances in 3rd generation CAR-T cells demonstrate a novel AND-Gate recognition mode that is based on the synNotch receptor $[16,17$, 19]. In synNotch receptor-mediated circuits, engagement of the synNotch receptor to the corresponding antigen can mediate the intramembrane cleavage to release the intracellular transcriptional activator domain. The application of the synNotch receptor system as an AND-Gate circuit requires binding to the corresponding antigen, which induces the expression of a second receptor (eg. CARs, TCRs or other proteins) that can mediate the killing of tumor cells. In preclinical experiments, synNotch receptormediated circuits drove expression of some anti-tumor molecules such as bispecific antibodies and cytokines. In this AND-Gate recognition approach, both antigens on the surface of tumor cells are required for T-cell activation and tumor elimination in a sustained manner, while a single tumor antigen does not. Versus CAR or TCR molecules that mediate the direct killing of tumor cells, synNotch receptor-mediated circuits provide a more precise and localized delivery system to target tumor cells $[16,17,19]$. Alternatively, Not-Gate circuits are based on the combination of an activator CAR (aCAR) mediated by one tumorkilling antigen with an inhibitory CAR (iCAR) by a second normal cell antigen. This approach can be applied in the negative discrimination against normal cell antigens, and effectively reduce cross-reactivity and potential toxicity [110]. Compared with the aCAR bearing an activating signaling domain in their intracellular regions, iCAR intracellular regions are derived from inhibitory receptors such as PD-1 and CTLA-4, and can transduce inhibitory signaling and exert an inhibitory effect on T-cell activation. For example, if a T-cell expressing aCAR and iCAR simultaneously encounters a tumor cell only expressing an aCAR but not iCAR antigen, then that T-cell can kill the select tumor cell. In contrast, if this same T-cell encounters a tumor cell expressing both aCAR and iCAR antigens, then iCAR-mediated inhibitory signaling will override or dampen the aCAR-mediated signaling, preserving that cell [110]. Such CAR-based NOT-Gate circuits therefore provide additional selectivity for therapeutic T-cells in their discrimination of non-cancer signals, resulting in more specific recognition and lower cross-reactivity. In a another iteration, CAR-based OR-Gate circuits are instead based on the CAR molecule bearing two independent antigen recognition domains, which can be activated by one of two different tumor-specific surface antigen ligands and induce the killing of tumor cells $[111,112]$. For example, such ORGate recognition has been used in the targeting of B-cell malignancies through engineering of CARs specific for CD19 and CD20. Result demonstrated that the CD19 and CD20-targeted CAR-based Gate circuits exhibit equally sensitive and efficient ability of killing tumor cells with or without expression of CD19 [112]. This OR-Gate recognition mode can thereby more efficiently target multiple tumor surface antigens, resulting in prevention of tumor resistance due to loss of tumor antigens. Together, given that the AND-, NOT-, and OR-Gate circuits can be applied to recognize tumor cells specifically through varied modes, it is feasible that co-application with varied CAR-based 
circuits to target tumor cells can provide even greater precision to cancer targeting in the future.

The fourth major consideration addresses remodeling of the immunosuppressive microenvironment to improve the efficacy of CAR-T cell therapy [18, 29, 113]. According to the tumor ecosystem perspective, the immunosuppressive microenvironment usually found in solid tumors plays a crucial promoting tumor immune evasion and growth [11]. As described previously [11, 114], similar to cancer clones, the immunosuppressive microenvironment is also heterogeneous, suggesting that appropriate and personalized countermeasures to target the specific tumor microenvironment is required for precision approaches. To block the effect of PD-1 mediated signaling, the extracellular domain of PD-1 has been previously fused to intracellular co-stimulatory domains, generating a chimeric receptor that can engage the normally suppressive PD-1 signal, but instead transduces a signal to enhance T-cell activity. Alternatively, removal of the PD-1 receptor in CAR-T cells through CRISPR genome-editing technology has been demonstrated to enhance the $\mathrm{T}$-cell response in the absence of PD-1 ligand-mediated signaling, suggesting that checkpoint inhibition can shape the immunosuppressive microenvironment alternatively via PD-1 or CTLA-4 mediated signaling. Additionally, incorporation of synNotchbased signaling systems, CAR-T cells can locally express and release a variety of payloads such as proinflammatory cytokines (for example, IL-12), checkpoint inhibitors and bispecific antibodies, which can also be used to remodel the tumor immunosuppressive microenvironment $[16,17,19]$.

Finally, the fifth consideration is design and implementation of desirable feedback control circuits that restrict the toxicity or hyperactivity of CAR-T cells [107, 115-117]. Toxicity and unregulated expansion and proliferation of CAR-T cell based approaches can lead to catastrophic clinical failure in vivo [118-120]. Technologies that can modulate transgene expression in a controlled manner, as well as activate or terminate T-cell function in vivo, are essential for the generation of CAR-T cells with controlled activity. To take advantage of immune stimulatory factors in boosting anti-cancer T-cell responses, it is also of crucial importance to control the timing and magnitude of the factor expression. For example, the level of IL- 6 release is an important indicator for evaluating the toxicity of cytokine release syndrome in CAR-T cell therapy, implying that a feedback circuit for detecting IL-6 levels is necessary for monitoring therapeutic toxicity [54]. To produce a controlled response of therapeutic T-cells, the following approaches have been considered: inducing suicide or elimination switches that can be potentially triggered by physicians to eliminate hyper-reactive T-cells at indicated time points [107, 108, 117], drug-controlled ON-Switch CARs that can control T-cell activity in a specific drugdependent manner $[54,121]$, or adaptor-mediated CARs that can target specific tumor cells through the binding of specific adaptor antibodies [122, 123]. In summary, for an effective and successful CAR-T-cell based immunotherapy, it is necessary to identify the critical functional challenges to address the target disease from multiple different dimensions: promoting logical design and engineering of CAR-T cells with desirable characteristics and functions in trafficking, proliferation and persistence, recognition and killing of tumor cells, remodeling the tumor microenvironment and regulatory control (Fig. 4c) [54].

\section{Genome-editing technology in engineering CAR-T cells}

In addition to gene transfer technologies widely used in cell biology, recent advancements in genome-editing technologies has led to enhanced efficacy and reduced toxicity of CAR-T cell therapy [124]. Genome-editing technologies that mainly include zinc-finger nucleases (ZFNs), transcription activator-like (TAL) effector nucleases (TALEN) and clustered regularly interspaced short palindromic repeats (CRISPR) approaches [125-127], provide a feasible method to add or remove functional genes in therapeutic T-cells, thereby engineering CAR-T cells with a variety of characteristics $[22,128]$. For example, exogenous TCRs expressed in engineered CAR-T cells can mismatch and compete with their endogenous TCRs, thus producing decreased activity and severe toxicity [129]. Engineered CAR-T cells with disruption of the endogenous TCR $\alpha$ and TCR $\beta$ genes by ZNFs have been shown to maintain antitumor activity in vivo, but did not produce off-target reactivity [57], demonstrating that genome-editing technology can equip CAR-T cells with an improved biosafety profiles. Recently, CRISPR/Cas9 genome-editing technology has been applied to redirect a CD19-specific CAR to the T-cell receptor $\alpha$ constant (TRAC) locus, resulting in uniform CAR-expressing T-cells [126]. Compared with conventionally generated CAR-T cells, these CRISPR/Cas9-edited CAR-T cells showed an enhanced potency, delayed differentiation and exhaustion of effector T-cells, highlighting the tremendous potential of genome-editing technology in the advancement of CAR-T cell therapy. Therefore, genomeediting technology is a highly promising approach to optimize the CAR-T cell therapy in the future.

\section{Combination of CAR-T cells with other therapeutics for cancer treatment}

To improve efficacy and decrease toxicity, the combination of CAR-T cell therapy with other therapeutics such as immune checkpoint inhibitors, chemotherapy, and other adjunct treatments have demonstrated promise (Fig. 4a) [130]. For example, prior to CAR-T cell therapy, lympho-depletion chemotherapy may promote antitumor activity via enhancing the T-cell response, killing suppressive immune cells, and optimizing the antigen presentation process [14]. Previous studies have also 
demonstrated that immune checkpoint related antibodies, such as anti-PD-1, PD-L1 and CTLA-4, when combined with CAR-T cells in solid tumors such as melanoma, and lung cancer, may produce an enhanced T-cell activity, with promising clinical outcomes [131].

\section{Conclusion}

CAR-T cell-based immunotherapy represents as a novel, powerful approach for tumor treatment, however several hurdles remain for therapeutic optimization. First, from the clonal-stromal-immune perspective, precision informatics of the tumor ecosystem (provided by "omics" approaches) is required for the successful programing and engineering of CAR-T cells. Armed with this information, we can then seek the answers to the following questions: what are the desirable tumor antigens that can be targeted by CAR-T cells? What are the immunosuppressive factors in the tumor ecosystem? How can we define the tumor's distinct cancer-immunity phenotype? What mechanisms do CAR-T cells use to evade immunity? This helps to identify the main functional challenges of CAR-T cell therapy so comprehensive measures at multiple dimensions can then be undertaken, including T-cell trafficking and infiltration, proliferation and persistence, targeted recognition of tumor antigens, remodeling the microenvironment and self-control regulation. Finally, in combination with other therapeutic measures, including genome-editing technology, immune checkpoint inhibitors, chemotherapy and cytokine treatment, an optimal, precision, CAR-T cell therapy can be designed and employed for individual cancer therapy. While CAR-T cell-based immunotherapeutics still face many challenges, we are beginning to define the horizon for an individualized cancer treatment.

\section{Acknowledgements}

This work was supported by the National Natural Science Foundation of China (No.81600101 to BX Ye, and No.81571147 to XX Xiong), an American Heart Association award 14FTF19970029 to CMS.

\section{Authors' contributions}

All authors read and approved the final manuscript.

\section{Competing interests}

The authors declare that they have no competing interests.

\section{Publisher's Note}

Springer Nature remains neutral with regard to jurisdictional claims in published maps and institutional affiliations.

\footnotetext{
Author details

${ }^{1}$ Department of Hematology, Renmin Hospital of Wuhan University, Wuhan, Hubei 430060, China. ${ }^{2}$ Department of Anesthesiology, Perioperative and Pain Medicine, Stanford University School of Medicine, Stanford, CA 94305-5117, USA. ${ }^{3}$ Department of Neurosurgery, Xiangya Hospital, Central south University, Changsha, Hunan 410008, China. ${ }^{4}$ Lab of Neuro-Oncology, Tianjin Neurological Institute, Key Laboratory of Post-Neuroinjury Neuro-repair and Regeneration in Central Nervous System, Tianjin, China. ${ }^{5}$ Department of Neurosurgery, Renmin Hospital of Wuhan University, Wuhan, Hubei 430060, China.
}

Received: 19 October 2017 Accepted: 9 February 2018

Published online: 15 February 2018

\section{References}

1. Weber J, Mandala M, Del Vecchio M, Gogas HJ, Arance AM, Cowey CL, Dalle S, Schenker M, Chiarion-Sileni V, Marquez-Rodas I, et al. Adjuvant Nivolumab versus Ipilimumab in resected stage III or IV melanoma. N Engl J Med. 2017; 377:1824-35.

2. Sonpavde G. PD-1 and PD-L1 inhibitors as salvage therapy for urothelial carcinoma. N Engl J Med. 2017;376:1073-4.

3. Long GV, Hauschild A, Santinami M, Atkinson V, Mandala M, Chiarion-Sileni V, Larkin J, Nyakas M, Dutriaux C, Haydon A, et al. Adjuvant Dabrafenib plus Trametinib in stage III BRAF-mutated melanoma. N Engl J Med. 2017;377: 1813-23.

4. Nghiem PT, Bhatia S, Lipson EJ, Kudchadkar RR, Miller NJ, Annamalai L, Berry S, Chartash EK, Daud A, Fling SP, et al. PD-1 blockade with Pembrolizumab in advanced Merkel-cell carcinoma. N Engl J Med. 2016;374:2542-52.

5. Ansell SM, Lesokhin AM, Borrello I, Halwani A, Scott EC, Gutierrez M, Schuster SJ, Millenson MM, Cattry D, Freeman GJ, et al. PD-1 blockade with nivolumab in relapsed or refractory Hodgkin's lymphoma. N Engl J Med. 2015;372:311-9.

6. Tran E, Longo DL, Urba WJ. A milestone for CAR T cells. N Engl J Med. 2017; 377:2593-6.

7. Sun C, Dotti G, Savoldo B. Utilizing cell-based therapeutics to overcome immune evasion in hematologic malignancies. Blood. 2016;127:3350-9.

8. Tirosh I, Izar B, Prakadan SM, Wadsworth MH 2nd, Treacy D, Trombetta JJ, Rotem A, Rodman C, Lian C, Murphy G, et al. Dissecting the multicellular ecosystem of metastatic melanoma by single-cell RNA-seq. Science. 2016; 352:189-96.

9. Horning SJ. A new cancer ecosystem. Science. 2017;355:1103.

10. Steidl C. The ecosystem of classical Hodgkin lymphoma. Blood. 2017;130:2360-1.

11. Dienstmann R, Vermeulen L, Guinney J, Kopetz S, Tejpar S, Tabernero J. Consensus molecular subtypes and the evolution of precision medicine in colorectal cancer. Nat Rev Cancer. 2017;17:79-92.

12. Prasad V. Immunotherapy: Tisagenlecleucel - the first approved CAR-T-cell therapy: implications for payers and policy makers. Nat Rev Clin Oncol. 2017;

13. Fujiwara $\mathrm{H}$. Adoptive immunotherapy for hematological malignancies using $T$ cells gene-modified to express tumor antigen-specific receptors. Pharmaceuticals (Basel). 2014;7:1049-68.

14. Park JH, Geyer MB, Brentjens RJ. CD19-targeted CAR T-cell therapeutics for hematologic malignancies: interpreting clinical outcomes to date. Blood. 2016;127:3312-20

15. Maus MV, Grupp SA, Porter DL, June CH. Antibody-modified T cells: CARs take the front seat for hematologic malignancies. Blood. 2014;123:2625-35.

16. Morsut L, Roybal KT, Xiong X, Gordley RM, Coyle SM, Thomson M, Lim WA. Engineering customized cell sensing and response behaviors using synthetic notch receptors. Cell. 2016;164:780-91.

17. Irvine DJ. A receptor for all occasions. Cell. 2016;164:599-600.

18. Boice M, Salloum D, Mourcin F, Sanghvi V, Amin R, Oricchio E, Jiang M, Mottok A, Denis-Lagache N, Ciriello G, et al. Loss of the HVEM tumor suppressor in lymphoma and restoration by modified CAR-T cells. Cell. 2016; 167:405-18. e413

19. Klebanoff CA, Restifo NP. Customizing functionality and payload delivery for receptor-engineered T cells. Cell. 2016;167:304-6.

20. Venteicher AS, Tirosh I, Hebert C, Yizhak K, Neftel C, Filbin MG, Hovestadt V, Escalante LE, Shaw ML, Rodman C, et al. Decoupling genetics, lineages, and microenvironment in IDH-mutant gliomas by single-cell RNA-seq. Science. 2017;355

21. Zheng C, Zheng L, Yoo JK, Guo H, Zhang Y, Guo X, Kang B, Hu R, Huang JY, Zhang $Q$, et al. Landscape of infiltrating $T$ cells in liver cancer revealed by single-cell sequencing. Cell. 2017;169:1342-56. e1316

22. Morris EC, Stauss HJ. Optimizing T-cell receptor gene therapy for hematologic malignancies. Blood. 2016;127:3305-11.

23. Ye B, Stary CM, Gao Q, Wang Q, Zeng Z, Jian Z, Gu L, Xiong X. Genetically modified T-cell-based adoptive immunotherapy in hematological malignancies. J Immunol Res. 2017;2017:5210459.

24. Sabaawy HE. Genetic heterogeneity and clonal evolution of tumor cells and their impact on precision cancer medicine. J Leuk (Los Angel). 2013;1:1000124.

25. Duan CW, Shi J, Chen J, Wang B, Yu YH, Qin X, Zhou XC, Cai YJ, Li ZQ, Zhang $F$, et al. Leukemia propagating cells rebuild an evolving niche in response to therapy. Cancer Cell. 2014;25:778-93. 
26. Gerlinger M, Rowan AJ, Horswell S, Larkin J, Endesfelder D, Gronroos E, Martinez P, Matthews N, Stewart A, Tarpey P, et al. Intratumor heterogeneity and branched evolution revealed by multiregion sequencing. N Engl J Med. 2012;366:883-92.

27. Ling S, Hu Z, Yang Z, Yang F, Li Y, Lin P, Chen K, Dong L, Cao L, Tao Y, et al. Extremely high genetic diversity in a single tumor points to prevalence of non-Darwinian cell evolution. Proc Natl Acad Sci U S A. 2015;112:E6496-505.

28. Jimenez-Sanchez A, Memon D, Pourpe S, Veeraraghavan H, Li Y, Vargas HA, Gill MB, Park KJ, Zivanovic O, Konner J, et al. Heterogeneous tumor-immune microenvironments among differentially growing metastases in an ovarian cancer patient. Cell. 2017;170:927-38. e920

29. Zhang B, Bowerman NA, Salama JK, Schmidt H, Spiotto MT, Schietinger A, Yu P, Fu YX, Weichselbaum RR, Rowley DA, et al. Induced sensitization of tumor stroma leads to eradication of established cancer by $T$ cells. J Exp Med. 2007:204:49-55.

30. Dienstmann R, Vermeulen L, Guinney J, Kopetz S, Tejpar S, Tabernero J. Consensus molecular subtypes and the evolution of precision medicine in colorectal cancer. Nat Rev Cancer. 2017;17:268.

31. Leffers N, Gooden MJ, de Jong RA, Hoogeboom BN, ten Hoor KA, Hollema $H$, Boezen HM, van der Zee AG, Daemen T, Nijman HW. Prognostic significance of tumor-infiltrating T-lymphocytes in primary and metastatic lesions of advanced stage ovarian cancer. Cancer Immunol Immunother. 2009;58:449-59.

32. Sato E, Olson SH, Ahn J, Bundy B, Nishikawa H, Qian F, Jungbluth AA, Frosina D, Gnjatic S, Ambrosone C, et al. Intraepithelial CD8+ tumorinfiltrating lymphocytes and a high CD8+/regulatory $T$ cell ratio are associated with favorable prognosis in ovarian cancer. Proc Natl Acad Sci U S A. 2005;102:18538-43.

33. Zhang L, Conejo-Garcia JR, Katsaros D, Gimotty PA, Massobrio M, Regnani G, Makrigiannakis A, Gray H, Schlienger K, Liebman MN, et al. Intratumoral T cells, recurrence, and survival in epithelial ovarian cancer. N Engl J Med. 2003;348:203-13.

34. Savage PA, Vosseller K, Kang C, Larimore K, Riedel E, Wojnoonski K, Jungbluth AA, Allison JP. Recognition of a ubiquitous self antigen by prostate cancer-infiltrating CD8+ T lymphocytes. Science. 2008;319:215-20.

35. Herbst RS, Soria JC, Kowanetz M, Fine GD, Hamid O, Gordon MS, Sosman JA, McDermott DF, Powderly JD, Gettinger SN, et al. Predictive correlates of response to the anti-PD-L1 antibody MPDL3280A in cancer patients. Nature. 2014:515:563-7.

36. Chen DS, Mellman I. Elements of cancer immunity and the cancer-immune set point. Nature. 2017;541:321-30.

37. Joyce JA, Fearon DT. T cell exclusion, immune privilege, and the tumor microenvironment. Science. 2015:348:74-80.

38. Salmon H, Franciszkiewicz K, Damotte D, Dieu-Nosjean MC, Validire $P$, Trautmann A, Mami-Chouaib F, Donnadieu E. Matrix architecture defines the preferential localization and migration of T cells into the stroma of human lung tumors. J Clin Invest. 2012:122:899-910.

39. Tumeh PC, Harview CL, Yearley JH, Shintaku IP, Taylor EJ, Robert L, Chmielowski B, Spasic M, Henry G, Ciobanu V, et al. PD-1 blockade induces responses by inhibiting adaptive immune resistance. Nature. 2014;515:568-71.

40. Armand P. Immune checkpoint blockade in hematologic malignancies. Blood. 2015;125:3393-400.

41. Chen DS, Mellman I. Oncology meets immunology: the cancer-immunity cycle. Immunity. 2013;39:1-10.

42. McGranahan N, Furness AJ, Rosenthal R, Ramskov S, Lyngaa R, Saini SK, Jamal-Hanjani M, Wilson GA, Birkbak NJ, Hiley CT, et al. Clonal neoantigens elicit T cell immunoreactivity and sensitivity to immune checkpoint blockade. Science. 2016;351:1463-9.

43. Hutchinson L. Immunotherapy: clonal neoantigens and immune response: a balancing act. Nat Rev Clin Oncol. 2016;13:265.

44. Sharma S, Stolina M, Yang SC, Baratelli F, Lin JF, Atianzar K, Luo J, Zhu L, Lin $Y$, Huang $M$, et al. Tumor cyclooxygenase 2-dependent suppression of dendritic cell function. Clin Cancer Res. 2003;9:961-8.

45. Pockaj BA, Basu GD, Pathangey LB, Gray RJ, Hernandez JL, Gendler SJ, Mukherjee P. Reduced T-cell and dendritic cell function is related to cyclooxygenase-2 overexpression and prostaglandin E2 secretion in patients with breast cancer. Ann Surg Oncol. 2004;11:328-39.

46. Mao Y, Sarhan D, Steven A, Seliger B, Kiessling R, Lundqvist A. Inhibition of tumor-derived prostaglandin-e2 blocks the induction of myeloid-derived suppressor cells and recovers natural killer cell activity. Clin Cancer Res. 2014;20:4096-106.
47. Kobie JJ, Wu RS, Kurt RA, Lou S, Adelman MK, Whitesell LI, Ramanathapuram LV, Arteaga CL, Akporiaye ET. Transforming growth factor beta inhibits the antigen-presenting functions and antitumor activity of dendritic cell vaccines. Cancer Res. 2003;63:1860-4.

48. Novitskiy SV, Pickup MW, Chytil A, Polosukhina D, Owens P, Moses HL. Deletion of TGF-beta signaling in myeloid cells enhances their antitumorigenic properties. J Leukoc Biol. 2012;92:641-51.

49. Gabrilovich DI, Chen HL, Girgis KR, Cunningham HT, Meny GM, Nadaf S, Kavanaugh D, Carbone DP. Production of vascular endothelial growth factor by human tumors inhibits the functional maturation of dendritic cells. Nat Med. 1996:2:1096-103.

50. Li J, Sun J, Rong R, Li L, Shang W, Song D, Feng G, Luo F: HMGB1 promotes myeloid-derived suppressor cells and renal cell carcinoma immune escape. Oncotarget 2017.

51. Ino $Y$, Yamazaki-Itoh $R$, Shimada $K$, Iwasaki $M$, Kosuge $T$, Kanai $Y$, Hiraoka N. Immune cell infiltration as an indicator of the immune microenvironment of pancreatic cancer. Br J Cancer. 2013;108:914-23.

52. Davoodzadeh Gholami M, Kardar GA, Saeedi Y, Heydari S, Garssen J, Falak R. Exhaustion of T lymphocytes in the tumor microenvironment: significance and effective mechanisms. Cell Immunol. 2017;322:1-14.

53. Catakovic K, Klieser E, Neureiter D, Geisberger R. T cell exhaustion: from pathophysiological basics to tumor immunotherapy. Cell Commun Signal. 2017;15:1

54. Lim WA, June $\mathrm{CH}$. The principles of engineering immune cells to treat cancer. Cell. 2017;168:724-40.

55. Gong MC, Latouche JB, Krause A, Heston WD, Bander NH, Sadelain M. Cancer patient $T$ cells genetically targeted to prostate-specific membrane antigen specifically lyse prostate cancer cells and release cytokines in response to prostate-specific membrane antigen. Neoplasia. 1999;1:123-7.

56. Fesnak AD, June $\mathrm{CH}$, Levine BL. Engineered T cells: the promise and challenges of cancer immunotherapy. Nat Rev Cancer. 2016;16:566-81.

57. Provasi E, Genovese P, Lombardo A, Magnani Z, Liu PQ, Reik A, Chu V, Paschon DE, Zhang L, Kuball J, et al. Editing T cell specificity towards leukemia by zinc finger nucleases and lentiviral gene transfer. Nat Med. 2012;18:807-15.

58. Brudno JN, Kochenderfer JN. Toxicities of chimeric antigen receptor T cells: recognition and management. Blood. 2016;127:3321-30.

59. Savoldo B, Ramos CA, Liu E, Mims MP, Keating MJ, Carrum G, Kamble RT, Bollard CM, Gee AP, Mei Z, et al. CD28 costimulation improves expansion and persistence of chimeric antigen receptor-modified T cells in lymphoma patients. J Clin Invest. 2011;121:1822-6.

60. Imai C, Mihara K, Andreansky M, Nicholson IC, Pui CH, Geiger TL, Campana D. Chimeric receptors with 4-1BB signaling capacity provoke potent cytotoxicity against acute lymphoblastic leukemia. Leukemia. 2004;18:676-84.

61. Kuhns MS, Davis MM, Garcia KC. Deconstructing the form and function of the TCR/CD3 complex. Immunity. 2006;24:133-9.

62. Long AH, Haso WM, Shern JF, Wanhainen KM, Murgai M, Ingaramo M, Smith JP, Walker AJ, Kohler ME, Venkateshwara VR, et al. 4-1BB costimulation ameliorates $T$ cell exhaustion induced by tonic signaling of chimeric antigen receptors. Nat Med. 2015;21:581-90.

63. Pule MA, Straath of KC, Dotti G, Heslop HE, Rooney CM, Brenner MK. A chimeric $T$ cell antigen receptor that augments cytokine release and supports clonal expansion of primary human T cells. Mol Ther. 2005;12:933-41.

64. Sadelain M, Brentjens R, Riviere I. The basic principles of chimeric antigen receptor design. Cancer Discov. 2013;3:388-98.

65. Guedan S, Chen X, Madar A, Carpenito C, McGettigan SE, Frigault MJ, Lee J, Posey AD Jr, Scholler J, Scholler $\mathrm{N}$, et al. ICOS-based chimeric antigen receptors program bipolar TH17/TH1 cells. Blood. 2014;124:1070-80.

66. Neelapu SS, Locke FL, Bartlett NL, Lekakis LJ, Miklos DB, Jacobson CA, Braunschweig I, Oluwole OO, Siddiqi T, Lin Y, et al. Axicabtagene Ciloleucel CAR T-cell therapy in refractory large B-cell lymphoma. N Engl J Med. 2017; 377:2531-44.

67. Schuster SJ, Svoboda J, Chong EA, Nasta SD, Mato AR, Anak O, Brogdon JL, Pruteanu-Malinici I, Bhoj $\mathrm{V}$, Landsburg D, et al. Chimeric antigen receptor $\mathrm{T}$ cells in refractory B-cell lymphomas. N Engl J Med. 2017;377:2545-54.

68. Mullighan CG, Phillips LA, Su X, Ma J, Miller CB, Shurtleff SA, Downing JR. Genomic analysis of the clonal origins of relapsed acute lymphoblastic leukemia. Science. 2008:322:1377-80.

69. Engel P, Zhou L, Ord DC, Sato S, Koller B, Tedder TF. Abnormal B lymphocyte development, activation, and differentiation in mice that lack or overexpress the CD19 signal transduction molecule. Immunity. 1995;3:39-50. 
70. Kochenderfer JN, Wilson WH, Janik JE, Dudley ME, Stetler-Stevenson M, Feldman SA, Maric I, Raffeld M, Nathan DA, Lanier BJ, et al. Eradication of B-lineage cells and regression of lymphoma in a patient treated with autologous $T$ cells genetically engineered to recognize CD19. Blood. 2010;116:4099-102.

71. Panjwani MK, Smith JB, Schutsky K, Gnanandarajah J, O'Connor CM, Powell DJ Jr, Mason NJ. Feasibility and safety of RNA-transfected CD20-specific chimeric antigen receptor $T$ cells in dogs with spontaneous B cell Iymphoma. Mol Ther. 2016;24:1602-14.

72. Wang CM, Wu ZQ, Wang Y, Guo YL, Dai HR, Wang XH, Li X, Zhang YJ, Zhang WY, Chen MX, et al. Autologous T cells expressing CD30 chimeric antigen receptors for relapsed or refractory Hodgkin lymphoma: an openlabel phase I trial. Clin Cancer Res. 2017;23:1156-66.

73. Minagawa K, Jamil MO, Al-Obaidi M, Pereboeva L, Salzman D, Erba HP, Lamb LS, Bhatia R, Mineishi S, Di Stasi A. In vitro pre-clinical validation of suicide gene modified anti-CD33 redirected chimeric antigen receptor T-cells for acute myeloid leukemia. PLoS One. 2016;11:e0166891.

74. Mardiros A, Forman SJ, Budde LE. T cells expressing CD123 chimeric antigen receptors for treatment of acute myeloid leukemia. Curr Opin Hematol. 2015;22:484-8.

75. Mardiros A, Dos Santos C, McDonald T, Brown CE, Wang X, Budde LE, Hoffman L, Aguilar B, Chang WC, Bretzlaff W, et al. T cells expressing CD123-specific chimeric antigen receptors exhibit specific cytolytic effector functions and antitumor effects against human acute myeloid leukemia. Blood. 2013;122: $3138-48$.

76. Mihara K, Yoshida T, Takei Y, Sasaki N, Takihara Y, Kuroda J, Ichinohe T. T cells bearing anti-CD19 and/or anti-CD38 chimeric antigen receptors effectively abrogate primary double-hit lymphoma cells. J Hematol Oncol. 2017;10:116.

77. Ormhoj M, Bedoya F, Frigault MJ, Maus MV. CARs in the lead against multiple myeloma. Curr Hematol Malig Rep. 2017;12:119-25.

78. Ritchie DS, Neeson PJ, Khot A, Peinert S, Tai T, Tainton K, Chen K, Shin M, Wall DM, Honemann D, et al. Persistence and efficacy of second generation CAR T cell against the LeY antigen in acute myeloid leukemia. Mol Ther. 2013;21:2122-9.

79. Panjwani MK, Smith JB, Schutsky K, Gnanandarajah J, O'Connor CM, Powell DJ Jr, Mason NJ. Feasibility and safety of RNA-transfected CD20-specific chimeric antigen receptor $T$ cells in dogs with spontaneous B cell lymphoma. Mol Ther. 2016;

80. Kenderian SS, Ruella M, Shestova O, Klichinsky M, Aikawa V, Morrissette JJ, Scholler J, Song D, Porter DL, Carroll M, et al. CD33-specific chimeric antigen receptor $T$ cells exhibit potent preclinical activity against human acute myeloid leukemia. Leukemia. 2015;29:1637-47.

81. Wang C, Wu Z, Wang Y, Guo Y, Dai H, Wang XH, Li X, Zhang YJ, Zhang WY, Chen MX, et al. Autologous T cells expressing CD30 chimeric antigen receptors for relapsed or refractory Hodgkin's lymphoma: an open-label phase I trial. Clin Cancer Res. 2016;

82. Wang L, Zhang S, Ou J, Bai H. Cytotoxity of pomalidomide combined CAR-T cell for multiple myeloma cell RPMI8226 and U266. Zhonghua Xue Ye Xue Za Zhi. 2015;36:497-500.

83. Ramos CA, Savoldo B, Torrano V, Ballard B, Zhang H, Dakhova O, Liu E, Carrum G, Kamble RT, Gee AP, et al. Clinical responses with T lymphocytes targeting malignancy-associated kappa light chains. J Clin Invest. 2016;126: 2588-96.

84. Thokala R, Olivares S, Mi T, Maiti S, Deniger D, Huls H, Torikai H, Singh H, Champlin RE, Laskowski T, et al. Redirecting specificity of T cells using the sleeping beauty system to express chimeric antigen receptors by mix-andmatching of VL and VH domains targeting CD123+ tumors. PLoS One. 2016; 11:e0159477.

85. Mihara K, Yanagihara K, Takigahira M, Kitanaka A, Imai C, Bhattacharyya J, Kubo T, Takei Y, Yasunaga S, Takihara Y, Kimura A. Synergistic and persistent effect of T-cell immunotherapy with anti-CD19 or anti-CD38 chimeric receptor in conjunction with rituximab on B-cell non-Hodgkin lymphoma. Br J Haematol. 2010;151:37-46.

86. Posey AD Jr, Schwab RD, Boesteanu AC, Steentoft C, Mandel U, Engels B, Stone JD, Madsen TD, Schreiber K, Haines KM, et al. Engineered CAR T cells targeting the cancer-associated Tn-Glycoform of the membrane mucin MUC1 control adenocarcinoma. Immunity. 2016;44:1444-54.

87. Blidner AG, Marino KV, Rabinovich GA, Driving CAR. Into sweet roads: targeting glycosylated antigens in cancer. Immunity. 2016;44:1248-50.

88. Liu H, Xu Y, Xiang J, Long L, Green S, Yang Z, Zimdahl B, Lu J, Cheng N, Horan LH, et al. Targeting alpha-fetoprotein (AFP)-MHC complex with CAR T-cell therapy for liver cancer. Clin Cancer Res. 2017;23:478-88.
89. Dao T, Pankov D, Scott A, Korontsvit T, Zakhaleva V, Xu Y, Xiang J, Yan S, de Morais Guerreiro MD, Veomett N, et al. Therapeutic bispecific T-cell engager antibody targeting the intracellular oncoprotein WT1. Nat Biotechnol. 2015; 33:1079-86.

90. Salter Al, Riddell SR. A BiTE from cancer's intracellular menu. Nat Biotechnol. 2015:33:1040-1.

91. Flemming A. Cancer: antitumour responses with more BiTE. Nat Rev Drug Discov. 2015;14:749.

92. Ataie N, Xiang J, Cheng N, Brea EJ, Lu W, Scheinberg DA, Liu C, Ng HL. Structure of a TCR-mimic antibody with target predicts pharmacogenetics. J Mol Biol. 2016;428:194-205.

93. Santich BH, Liu H, Liu C, Cheung NK. Generation of TCR-like antibodies using phage display. Methods Mol Biol. 2015;1348:191-204.

94. Ma Q, Garber HR, Lu S, He H, Tallis E, Ding X, Sergeeva A, Wood MS, Dotti G, Salvado $B$, et al. A novel TCR-like CAR with specificity for PR1/HLA-A2 effectively targets myeloid leukemia in vitro when expressed in human adult peripheral blood and cord blood T cells. Cytotherapy. 2016;18:985-94.

95. Haiying Qin SMN, Ramakrishna S, Tarun S, Yang L, Verdini NP, Haso W, Terry J. Fry: novel CD19/CD22 Bicistronic chimeric antigen receptors outperform single or bivalent Cars in eradicating CD19+CD22+, CD19-, and CD22- pre-B leukemia. Blood. 2017:130

96. Liang Huang NW, Li C, Cao Y, Xiao Y, Xiao M, Zhang Y, Zhang T, Zhou J. Sequential infusion of anti-CD22 and anti-CD19 chimeric antigen receptor $\mathrm{T}$ cells for adult patients with refractory/relapsed B-cell acute lymphoblastic leukemia. Blood. 2017;130

97. Ahmed N, Brawley VS, Hegde M, Robertson C, Ghazi A, Gerken C, Liu E, Dakhova O, Ashoori A, Corder A, et al. Human epidermal growth factor receptor 2 (HER2) -specific chimeric antigen receptor-modified T cells for the immunotherapy of HER2-positive sarcoma. J Clin Oncol. 2015;33: 1688-96.

98. Kershaw MH, Westwood JA, Parker LL, Wang G, Eshhar Z, Mavroukakis SA, White DE, Wunderlich JR, Canevari S, Rogers-Freezer L, et al. A phase I study on adoptive immunotherapy using gene-modified $T$ cells for ovarian cancer. Clin Cancer Res. 2006;12:6106-15.

99. Teachey DT, Lacey SF, Shaw PA, Melenhorst JJ, Maude SL, Frey N, Pequignot E, Gonzalez VE, Chen F, Finklestein J, et al. Identification of predictive biomarkers for cytokine release syndrome after chimeric antigen receptor Tcell therapy for acute lymphoblastic leukemia. Cancer Discov. 2016;6:664-79.

100. Di Stasi A, De Angelis B, Rooney CM, Zhang L, Mahendravada A, Foster AE, Heslop HE, Brenner MK, Dotti G, Savoldo B. T lymphocytes coexpressing CCR4 and a chimeric antigen receptor targeting CD30 have improved homing and antitumor activity in a Hodgkin tumor model. Blood. 2009;113: 6392-402.

101. Aldinucci D, Pinto A, Gloghini A, Carbone A. Chemokine receptors as therapeutic tools in Hodgkin lymphoma: CCR4 and beyond. Blood. 2010; 115:746-7. author reply 748

102. Till BG, Jensen MC, Wang J, Chen EY, Wood BL, Greisman HA, Qian X, James SE, Raubitschek A, Forman SJ, et al. Adoptive immunotherapy for indolent non-Hodgkin lymphoma and mantle cell lymphoma using genetically modified autologous CD20-specific T cells. Blood. 2008;112:2261-71.

103. Pule MA, Savoldo B, Myers GD, Rossig C, Russell HV, Dotti G, Huls MH, Liu E, Gee AP, Mei Z, et al. Virus-specific T cells engineered to coexpress tumorspecific receptors: persistence and antitumor activity in individuals with neuroblastoma. Nat Med. 2008;14:1264-70.

104. Gajewski TF. The next hurdle in cancer immunotherapy: overcoming the non-T-cell-inflamed tumor microenvironment. Semin Oncol. 2015;42:663-71.

105. Turley SJ, Cremasco V, Astarita JL. Immunological hallmarks of stromal cells in the tumour microenvironment. Nat Rev Immunol. 2015;15:669-82.

106. Ninomiya S, Narala N, Huye L, Yagyu S, Savoldo B, Dotti G, Heslop HE, Brenner MK, Rooney CM, Ramos CA. Tumor indoleamine 2,3-dioxygenase (IDO) inhibits CD19-CAR T cells and is downregulated by lymphodepleting drugs. Blood. 2015;125:3905-16.

107. Di Stasi A, Tey SK, Dotti G, Fujita Y, Kennedy-Nasser A, Martinez C, Straathof K, Liu E, Durett AG, Grilley B, et al. Inducible apoptosis as a safety switch for adoptive cell therapy. N Engl J Med. 2011;365:1673-83.

108. Sadelain M. Eliminating cells gone astray. N Engl J Med. 2011;365:1735-7.

109. Moon EK, Carpenito C, Sun J, Wang LC, Kapoor V, Predina J, Powell DJ Jr, Riley JL, June $\mathrm{CH}$, Albelda SM. Expression of a functional CCR2 receptor enhances tumor localization and tumor eradication by retargeted human $\mathrm{T}$ cells expressing a mesothelin-specific chimeric antibody receptor. Clin Cancer Res. 2011;17:4719-30. 
110. Fedorov VD, Themeli M, Sadelain M. PD-1- and CTLA-4-based inhibitory chimeric antigen receptors (iCARs) divert off-target immunotherapy responses. Sci Transl Med. 2013;5:215ra172.

111. Grada Z, Hegde M, Byrd T, Shaffer DR, Ghazi A, Brawley VS, Corder A, Schonfeld K, Koch J, Dotti G, et al. TanCAR: a novel bispecific chimeric antigen receptor for cancer immunotherapy. Mol Ther Nucleic Acids. 2013;2:e105.

112. Zah E, Lin MY, Silva-Benedict A, Jensen MC, Chen YY, Cells Expressing T. CD19/CD20 bispecific chimeric antigen receptors prevent antigen escape by malignant B cells. Cancer Immunol Res. 2016;4:498-508.

113. Engels B, Rowley DA, Schreiber H. Targeting stroma to treat cancers. Semin Cancer Biol. 2012;22:41-9.

114. McGranahan N, Swanton C. Clonal heterogeneity and tumor evolution: past, present, and the future. Cell. 2017;168:613-28.

115. Diaconu I, Ballard B, Zhang M, Chen Y, West J, Dotti G, Savoldo B. Inducible Caspase-9 selectively modulates the toxicities of CD19-specific chimeric antigen receptor-modified T cells. Mol Ther. 2017;25:580-92.

116. Straathof KC, Pule MA, Yotnda P, Dotti G, Vanin EF, Brenner MK, Heslop HE, Spencer DM, Rooney CM. An inducible caspase 9 safety switch for T-cell therapy. Blood. 2005;105:4247-54.

117. Zhou X, Brenner MK. Improving the safety of T-cell therapies using an inducible caspase-9 gene. Exp Hematol. 2016;44:1013-9.

118. Zhang L, Morgan RA, Beane JD, Zheng Z, Dudley ME, Kassim SH, Nahvi AV, Ngo LT, Sherry RM, Phan GQ, et al. Tumor-infiltrating lymphocytes genetically engineered with an inducible gene encoding interleukin-12 for the immunotherapy of metastatic melanoma. Clin Cancer Res. 2015;21: 2278-88.

119. Klebanoff CA, Finkelstein SE, Surman DR, Lichtman MK, Gattinoni L, Theoret MR, Grewal N, Spiess PJ, Antony PA, Palmer DC, et al. IL-15 enhances the in vivo antitumor activity of tumor-reactive CD8+ T cells. Proc Natl Acad Sci U S A. 2004;101:1969-74.

120. Hsu C, Jones SA, Cohen CJ, Zheng Z, Kerstann K, Zhou J, Robbins PF, Peng PD, Shen X, Gomes TJ, et al. Cytokine-independent growth and clonal expansion of a primary human CD8+ T-cell clone following retroviral transduction with the IL-15 gene. Blood. 2007;109:5168-77.

121. Wu CY, Roybal KT, Puchner EM, Onuffer J, Lim WA. Remote control of therapeutic T cells through a small molecule-gated chimeric receptor. Science. 2015;350:aab4077.

122. Ma JS, Kim JY, Kazane SA, Choi SH, Yun HY, Kim MS, Rodgers DT, Pugh HM, Singer $\mathrm{O}$, Sun SB, et al. Versatile strategy for controlling the specificity and activity of engineered T cells. Proc Natl Acad Sci U S A. 2016;113:E450-8.

123. Rodgers DT, Mazagova M, Hampton EN, Cao Y, Ramadoss NS, Hardy IR, Schulman A, Du J, Wang F, Singer O, et al. Switch-mediated activation and retargeting of CAR-T cells for B-cell malignancies. Proc Natl Acad Sci U S A. 2016:113:E459-68.

124. Ren J, Zhang $X$, Liu $X$, Fang $C$, Jiang $S$, June $C H$, Zhao $Y$. A versatile system for rapid multiplex genome-edited CAR T cell generation. Oncotarget. 2017; 8:17002-11.

125. Qasim W, Zhan H, Samarasinghe S, Adams S, Amrolia P, Stafford S, Butler K, Rivat C, Wright G, Somana K, et al. Molecular remission of infant B-ALL after infusion of universal TALEN gene-edited CAR T cells. Sci Transl Med. 2017;9

126. Eyquem J, Mansilla-Soto J, Giavridis T, van der Stegen SJ, Hamieh M, Cunanan KM, Odak A, Gonen M, Sadelain M. Targeting a CAR to the TRAC locus with CRISPR/Cas9 enhances tumour rejection. Nature. 2017;543:113-7.

127. Liu X, Zhang Y, Cheng C, Cheng AW, Zhang X, Li N, Xia C, Wei X, Liu X, Wang H. CRISPR-Cas9-mediated multiplex gene editing in CAR-T cells. Cell Res. 2017;27:154-7.

128. Hoban MD, Bauer DE. A genome editing primer for the hematologist. Blood. 2016;127:2525-35

129. Torikai H, Reik A, Liu PQ, Zhou Y, Zhang L, Maiti S, Huls H, Miller JC, Kebriaei $\mathrm{P}$, Rabinovich B, et al. A foundation for universal T-cell based immunotherapy: T cells engineered to express a CD19-specific chimericantigen-receptor and eliminate expression of endogenous TCR. Blood. 2012; 119:5697-705

130. Heczey A, Louis CU, Savoldo B, Dakhova O, Durett A, Grilley B, Liu H, Wu MF, Mei Z, Gee A, et al. CAR T cells administered in combination with Lymphodepletion and PD-1 inhibition to patients with neuroblastoma. Mol Ther. 2017;

131. Chong EA, Melenhorst JJ, Lacey SF, Ambrose DE, Gonzalez V, Levine BL, June $\mathrm{CH}$, Schuster SJ. PD-1 blockade modulates chimeric antigen receptor (CAR)-modified T cells: refueling the CAR. Blood. 2017;129:1039-41.

\section{Submit your next manuscript to BioMed Central and we will help you at every step:}

- We accept pre-submission inquiries

- Our selector tool helps you to find the most relevant journal

- We provide round the clock customer support

- Convenient online submission

- Thorough peer review

- Inclusion in PubMed and all major indexing services

- Maximum visibility for your research

Submit your manuscript at www.biomedcentral.com/submit
Biomed Central 